\title{
SJoP
}

\section{Listen to the others: the rehearsal process as a constant act of care}

\section{INÊS BENTO-COELHO}

The Scottish Journal of Performance

Volume 5, Issue 1; April 2018

ISSN: 2054-1953 (Print) / ISSN: 2054-1961 (Online)

Publication details: http://www.scottishjournalofperformance.org

To cite this article: Bento-Coelho, I., 2018. Listen to the others: the rehearsal process as a constant act of care. Scottish Journal of

Performance, 5(1): pp.63-81.

To link to this article: http://doi.org/10.14439/sjop.2018.0501.06

\footnotetext{
(C)

This work is licensed under a Creative Commons

Attribution 4.0 International License. See

http://creativecommons.org/licenses/by/4.0/ for details.
} 


\section{Listen to the others: the rehearsal process as a constant act of care}

INÊS BENTO-COELHO

DOI: 10.14439/sjop.2018.0501.06

Publication date: 6 April 2018

While artists and performance makers use different strategies when engaging with participants in the rehearsal room, their presence provides the practitioner with a chance to care and ethically embed the other's agency in the making process. In performance, care has often been discussed in the context of performance's relationship with the viewer. In this article, I argue for listening as a rehearsal practice using a framework grounded in care. I propose DAR-Direction, Action, and Reflection, a way of making which fosters awareness of the other-that may be incorporated, adapted, and applied by practitioners across different creative fields. I discuss the rehearsal process of This is Not About Dance, a performative installation presented at the Reid Gallery in 2016, to argue for a conception of the rehearsal as a constant act of care, one that has the potential to grow one's practice through colistening.

Keywords: care, rehearsal, process, listening, performance, reflection, awareness, collaboration.

\section{Introduction}

In performance practice, listening is often interpreted as a metaphor for awareness, a strategy to enhance our understanding of the world. While composers (Buzzarté and Bickley, 2012), sound artists (Voegelin, 2010), and somatic practices (Eddy, 2009) for instance align with specific 
nuances of the listening activity, the literature reveals little discussion on its potential within the rehearsal process. Working alone in the studio, the practitioner is responsible for the work and the self, often focusing on the work's development. Working with participants enables the performance maker to incorporate their viewpoints into the work. Although creative processes can differ greatly amongst performance practitioners when engaging with others, their presence creates a chance for makers to listen even more carefully, and to care. While care in performance has been examined in the context of the performance event itself (Johnson, 2016), few studies address care within the rehearsal environment. Nonetheless, considering a care practice (Tronto, 1993) where the practitioner aims to unveil the reality of the other person (Noddings, 1984) offers a framework for performance makers to adopt an inclusive approach in the rehearsal context. The emphasis on awareness of the other during rehearsals lays the foundation for an understanding of the rehearsal process as a constant act of care.

In this article, I focus particularly on rehearsals for performative installations with a site-responsive component, the area of practice where my work is situated. I begin with a discussion of the piece This is Not About Dance, This is Not About Movement, This is Not About Performance to argue for an understanding of listening as a rehearsal practice. I discuss how the different nuances of a listening practice have been approached by various artists, and propose a view of listening as an act of conscious engagement with the world around us (Voegelin, 2010). I address the potential of listening in the rehearsal setting, proposing a care framework entitled DAR-Direction, Action, and Reflection-a method of making which fosters awareness of the other. The framework emphasises the facilitator approach in the Reflection step, opening a space for participants to engage actively with how the work takes shape. The analysis of making This is Not About Dance 
demonstrates how the Reflection step enables the performance maker to uncover new layers, only reachable through careful dialogical sharing. Reflection opens a forum for co-listening throughout the rehearsal, creating distinct ways to consider what collaboration is. The DAR approach may be incorporated, adapted, and applied by practitioners across different fields, such as dance, theatre and live art. Listening to the other has the potential to enhance the participants' agency in rehearsal, and perhaps in performance, although the latter is outwith the remit of this study. Furthermore, listening to the other can positively contribute to the development of performance work in an ethical and supportive manner, opening new avenues for creation while engaging the participants in the process.

\section{A performative installation: This is Not About}

\section{Dance}

This is Not About Dance, presented in 2016 at the Reid Gallery in The Glasgow School of Art, focuses on presence and spatial awareness, exploring how the human body activates space through everyday movement. It was performed by five participants with different backgrounds and levels of experience-painting and performance students and graduates, a curator, and a dancer-wearing bright plain costumes in blue, red, or green, enhancing the notion of a live painting or sculpture. Performers stood still for five minutes (Fig. 1), then walked in straight lines, paused, and changed direction, generating new spatial configurations. Performed over twenty minutes within and outwith the gallery, the piece is structured as alternating choreographed and improvised sequences separated by a few minutes of stillness. During the work, performers listened to the environment, to each other, and to the audience, responding to their surroundings as they made decisions on when and where to walk, turn, or stop, within a geometric set of lines, points, and intersections (Figs. 2 and 3). Each score was different: performers engaged with the 
whole space, a particular area, or in specific configurations, and started and finished in a different location as the piece travelled throughout the gallery. The work resembles the formal repetition in Samuel Beckett's television play Quad (1981), Trisha Brown's proposition of how we perceive movement in Walking on the Wall (1971), and Anne Truit's minimalist sculptures from the seventies.

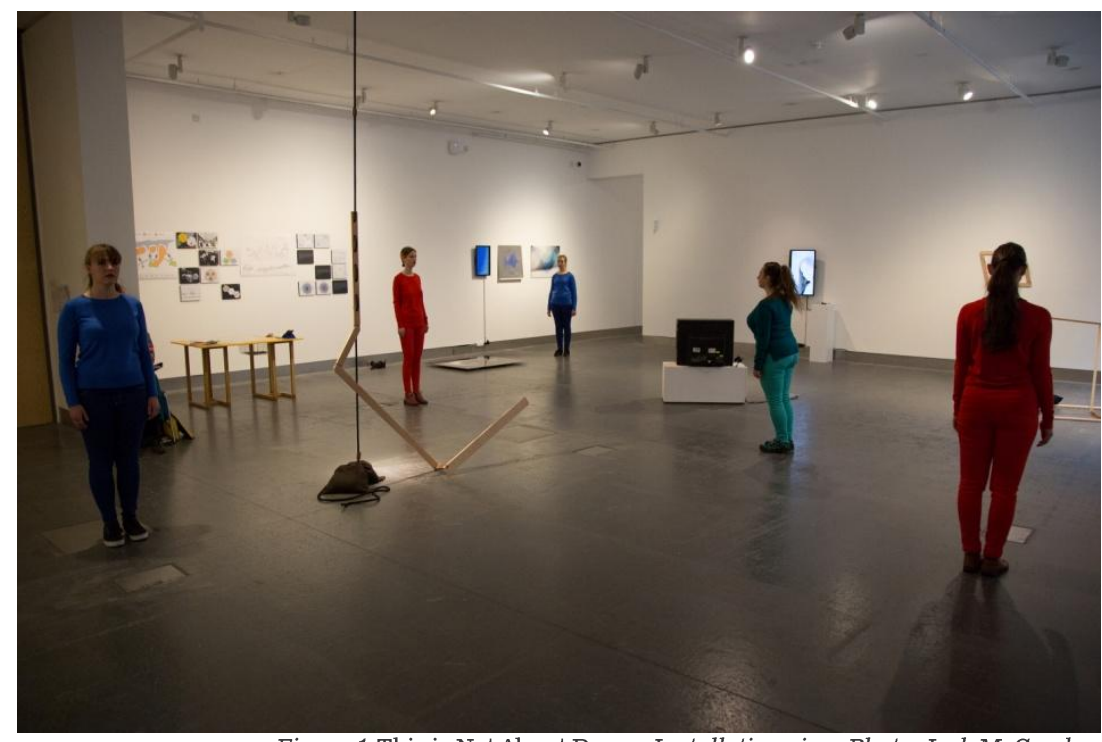

Figure 1: This is Not About Dance. Installation view. Photo: Jack McCombe.

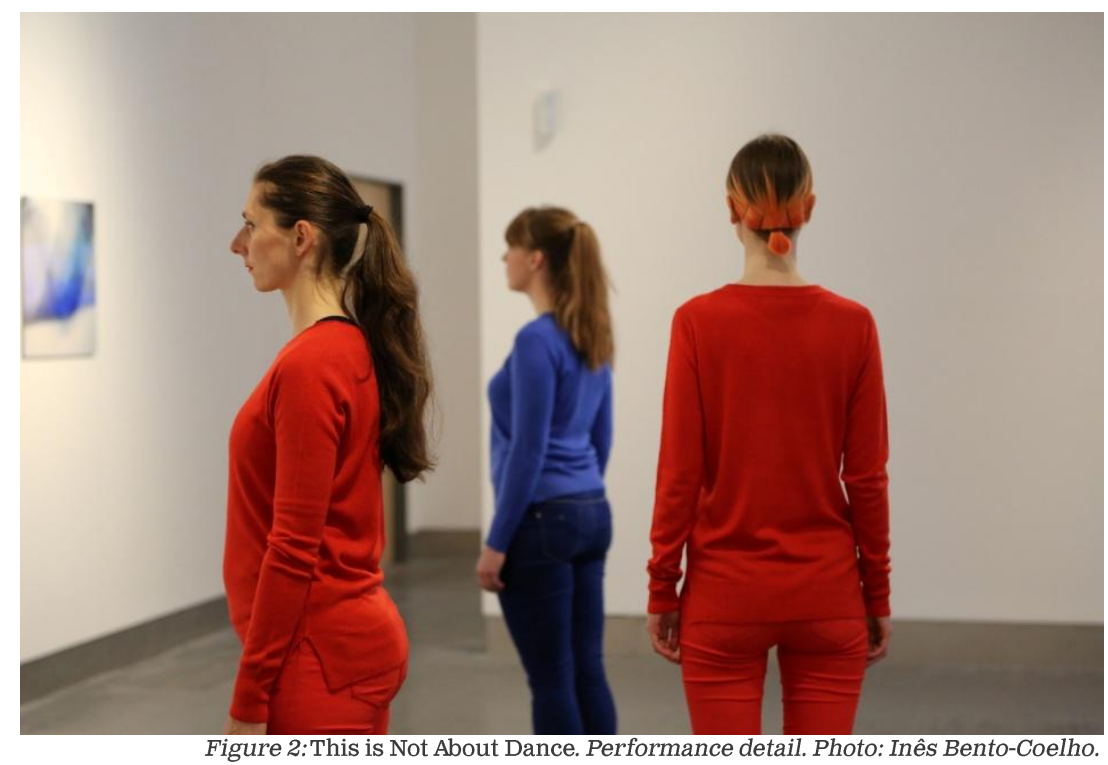




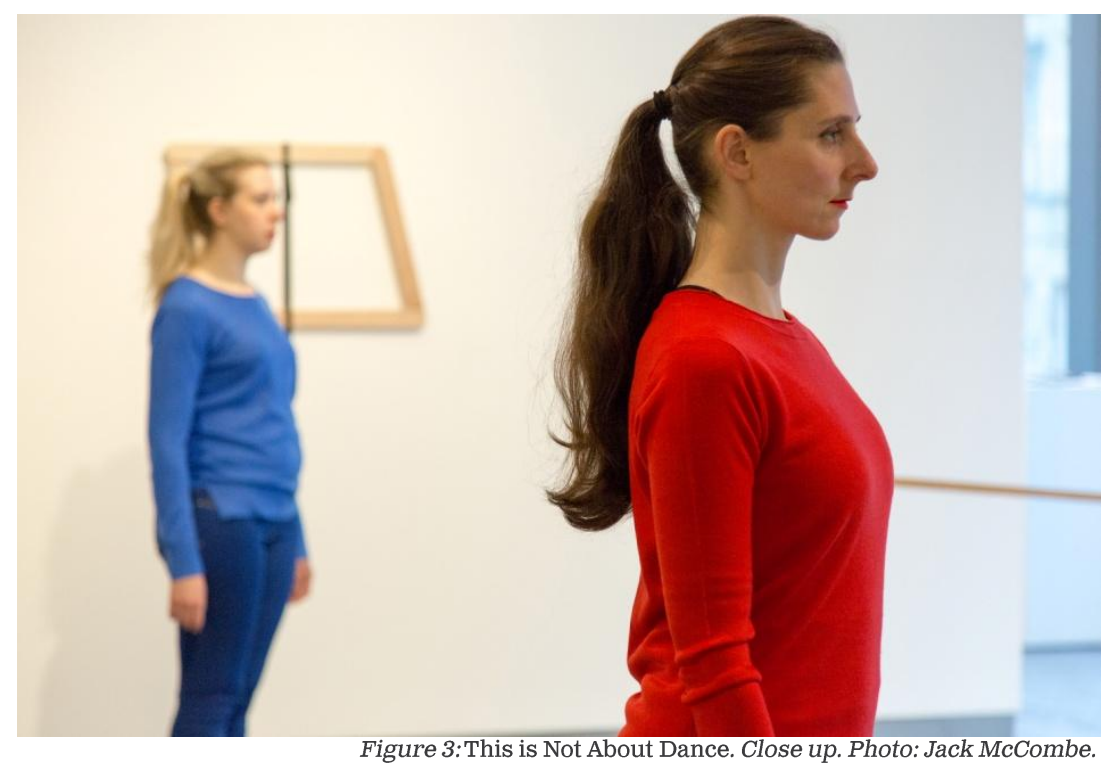

In This is Not About Dance, I use walking as a composition material to explore how the performers' bodies relate to the space in which they perform. German-American phenomenologist Erwin Strauss (1966) suggests that while dancing, a person moves 'within' space, whereas walking is a means to 'traverse' space. By considering walking as dancing, transporting the walk into a performative environment where performers move 'within' space, participants engage in a distinct relationship with the gallery: they dance. However, their gestures lie at the intersection of choreographed movement and the everyday, as explored by the Judson Dance Theatre in the 1960s (Childs, 2003). Brown writes 'I may perform an everyday gesture so that the audience does not know whether I have stopped dancing or not' (1975, p.61). This is Not About Dance sits at the boundaries of dance, performance, and sitespecific installation; a choreographic sculpture that is simultaneously static and moving, fostering new relationships with the gallery environment.

\section{Listening as a rehearsal practice}

Listening in performance has been approached by somatic practices, sound artists, and composers in different ways. 
Somatic practices focus on listening to the body as a process to develop awareness of movement (Eddy, 2009), often for therapeutic purposes. The Alexander Technique and the Feldenkrais Method for instance, attend to movement perception to improve well-being, while Body-Mind Centering fosters a greater sense of self-awareness by focusing on the relationships between body and mind. In Listening to Noise and Silence, Salomé Voegelin (2010) talks about listening as a process used to navigate and explore a sound artwork, as opposed to passively receiving it. For her, listening is an active act of discovery: 'What I hear is discovered not received' (2010, p.4). This engagement with listening was widely studied by composer Pauline Oliveros, the founder of Deep Listening practice. She describes it as an intense activity of listening to all possible sounds in all possible ways, regardless of what one is doing (see Buzzarté and Bickley, 2012). Heloise Gold considers Deep Listening as a practice that allows one to 'become present, and to respond spontaneously and creatively from a deep source or wakefulness' (Gold, 2012, p.149). She discusses the concept of a 'listening body' as an activity where the whole body listens as if one had ears in every cell, a practice that allows one to 'respond more sensitively and immediately' (Gold, 2012, p.150). While Deep Listening is focused on listening to sound and somatic practices attend to listening to movement through the body, I propose to shift the focus of listening-from sound and movement-towards the surroundings. I consider listening as a form of perception that allows one to carefully pay attention to the other, the space, and the work, in the sense of Voegelin's (2010) understanding of listening as an active mode of engagement with the world, and Gold's (2012) view of listening as a form of presence. As such, listening is an open framework for awareness of, and engagement with several aspects of performance practice: the performers, the space, the work, and the self. 
A listening framework has potential for practitioners to embed a position of care within it. Care, a difficult concept to pinpoint, has been interpreted in distinct ways by several authors (Sander-Staudt, n.d.). Carol Gilligan and Nel Noddings (Sander-Staudt, n.d.) proposed care ethics in the 1980 s as a theory essentially underlined by moral fundamentals. Noddings (1984) argues that care forms the basics of an ethical response, a reciprocal relationship, one that sits at the foundation of human existence (SanderStaudt, n.d.). For her, ethical caring is 'the relation in which we do meet the other morally' (Noddings, 1984, p.4), and she further describes care as a form of accessing the other person's reality. Amongst the philosophers who propose care as a form of practice, Joan Tronto and Berenice Fischer define it as:

... a species of activity that includes everything we do to maintain, contain, and repair our "world" so that we can live in it as well as possible. That world includes our bodies, ourselves, and our environment, all of which we seek to interweave in a complex, life-sustaining web (Tronto, 1993, p.103).

While Tronto's approach to care has been criticised for being too broad (Sander-Staudt, n.d.), considering it as a practice allows us to integrate it in other domains of action and interaction, such as the rehearsal process. In rehearsal, care requires the practitioner to engage deeply with the participants they work with, requesting a level of involvement for 'reaching out to something other than the self' (Tronto, 1993, p.102). In privileging the focus on engagement with the surroundings, a sense of paying attention to the other, care aligns with Voegelin's (2010) understanding of listening as an active mode of engagement with the world. 
Adrian Howells' approach to the other is an example of listening as care in performance practice. His ability to 'really listen and sense what his audience needed' is a key aspect of his one-to-one performances and reflects his 'uncompromising duty of care': his interest in reaching out to the other led him to create safe spaces for the encounter with the audience during performance (Hastings and Wylie, 2016, p.253). In my approach, a listening framework grounded in care allows me to pay close attention to the performers during the making process.

Noyale Colin and Stephanie Sachsenmaier propose a useful understanding of collaborative processes in performance practice as approaches that 'embrace the unknowable at its outset, in that they entail encounters with any given "others" [...] inherently productive in creative terms' (2016, pp.15-16). The rehearsals become a ground for a dynamic encounter with performers: safe spaces, where their perceptions, ideas, and thoughts can be transferred to the work through a process of active attentiveness. Colin and Sachsenmaier further describe collaborative performance practice as 'characterized by a significant input on behalf of the performers' to develop the work's material (2016, pp.8-9). As care implicitly leads to an action (Tronto, 1993), listening to the performers' thoughts enables me to integrate them in the activities and the decision-making process, tailoring my actions to the participants' requirements, interweaving their agency in the artwork's complexity, thus re-enforcing the argument for the rehearsal as a constant act of care.

Listening to the other is therefore central to my rehearsal practice. While several practitioners structure the rehearsal around three main activities-directing, performing tasks, and discussing material-I incorporate an element of care in my process. I developed the $D A R$ approach with a constant collaborative dialogical reflection at its core. Like any other rehearsal, the session starts with introducing the tasks to 
participants, the Direction; followed by the participants' response to the tasks, the Action; followed by gathering the group for dialogical Reflection. This process is repeated several times until the rehearsal finishes. DAR-which in my first language, Portuguese, means giving or offeringemphasises a caring outlook in all stages, supporting the wellbeing of performers and makers through providing them opportunities to give through listening. Performers show emerging material while I observe, take notes, and listen, paying attention to what they do and how their bodies act in the space: physical observation. I am also aware of their emotional involvement in the work: emotional observation. In performance, Howells creates safe spaces 'for the work to thrive' (quoted in Johnson, 2016, p.115); I create safe spaces in the rehearsal context, where participants explore and take risks within their own limits. My decision-making contributes to a caring environment, as I attend to how much longer to spend on a section, whether participants appear to need a break, or whether a change in approach is necessary. Throughout the framework, I facilitate collaborative exercises where performers devise movement material; direct the development of the material generated, run rehearsals, and make creative and logistic decisions; facilitate dialogical reflections for participants to share views on the process and the work; choreograph the material devised collaboratively; and make decisions on the work's visual qualities. In This is Not About Dance, for example, the different roles at specific moments-director, choreographer, and facilitator-reflect the nature of nontraditional approaches to complex contemporary and changing practices operating within the gallery context. Colin and Sachsenmaier (2016) discuss the shift of the director / choreographer's role in performance towards a facilitator role as a key element in contemporary practice. The DAR framework further contributes to this complexity, valuing the facilitator approach with specific goals at particular moments. 


\section{Reflection as a listening platform for a care practice}

The rehearsals for This is Not About Dance followed a practice of listening through the $D A R$ approach. In the dialogical Reflection step (Fig. 4), I took a facilitator role offering an open and supportive space for participants to share their thoughts. Regular dialogical Reflection enables participants to take agency within the process, and supports two goals: it allows me to listen to the performers' experience of the work and to identify challenges, and it enables their experiences to emerge and permeate the work. Throughout the conversations I infer what participants need, I consider how to better support them, and I integrate their contribution into the piece, as learning how participants perceive the work contributes to the making of it. These conversations inform the next Direction: attending to the performers' views opens possibilities for change in the work. The Reflection moment is instrumental in accessing their reality through care for the other, using Noddings' proposition of ethical caring (1984).

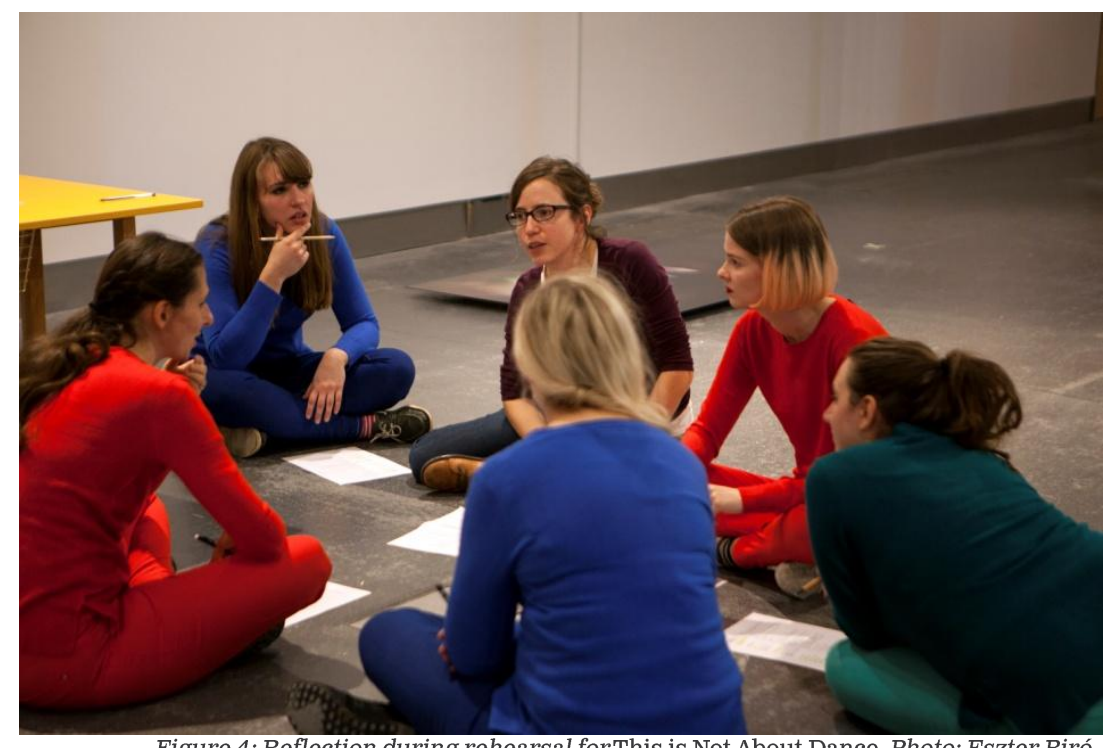

Figure 4: Reflection during rehearsal for This is Not About Dance. Photo: Eszter Biró.

During the rehearsals for This is Not About Dance, performers were instructed to listen to the space and to one 
another. I began each rehearsal with warm up exercises to enhance awareness of the body, the space, and the other. In an exercise, participants walked side by side in a straight line. I integrated variations, such as stopping, and walking together at different speeds or with the eyes closed. The latter instigates awareness of each other in the space, as participants concentrate on listening to the others' sounds to know where they are. An invisible connection between performers is stimulated, fostering an awareness mind-set that becomes perceptible throughout the work. The warm up was followed by exercises where participants choreographed scores in small groups based on walking, turning, and stillness through paying attention to their surroundings. Performers created movement as opposed to working with pre-defined scores: a personal relationship with the material is thus fostered, and connections built between performers. The rehearsals finished with improvisation practice.

The development of the piece's structure exemplifies how the listening framework guided the decision-making in This is Not About Dance from an ethical and careful position. In the first rehearsal, I instructed participants to improvise with walking, pausing, and turning in response to one another; observe the improvisation from the outside; and gather to share insights. I asked, 'what did you find when you were watching the others?', and facilitated a space for participants to share their perceptions of the work, placing them briefly in the director's role with the potential to bring their agency into the piece. One performer said, 'she turns, and you know, I need to be ready [...] it is quite exciting inside [yourself ][...] if you relate [...] because you have to listen more' (anonymous 2016, personal communication, 6 October 2016). The exercise required participants to be present in the space, to be connected and alert, to listen to one another at all times. Another participant remarked: 'structure will be really useful in terms of the duration, because I think it will be really easy to lose track [...], it is 
hard to say how much time has passed' (anonymous 2016, personal communication, 6 October 2016). While the improvised sections hold a strong sense of presence and awareness, throughout the dialogical Reflections, participants mentioned a need for a recognisable structure to hold on to and feel confident. Attending to their perception of the piece's nuances contributed to my decision to alternate choreographed and improvised scores in the work's structure, creating a situation where participants would feel supported. The choreographed sections provided a sense of security within the work, a platform from which performers could improvise with confidence, responding to one another, the audience, and the space. Tronto's four concepts of ethical care-attentiveness, responsibility, competence, and responsiveness (1993)-closely relate to listening to the other within rehearsal. In particular, attentiveness, paying attention to and recognising the needs of those around us (Tronto, 1993), enables me to make decisions from a care and ethical standpoint. It allows me to identify how participants see the work, and value their understanding of the piece. The Reflection step can be fundamental in developing work operating from a listening framework embedded in care, in an ethical manner, allowing the work to adapt to the participants, enabling their agency to permeate the piece.

Larry Lavender discusses three main points at the core of using dialogical approaches when teaching choreography:

the activation of artist, performer, and the spectator in order to foster through the experience of art a greater agency; shared authorship that cedes to others some or all control of a work's structure and meaning; and a notion of community as collective responsibility, a view that is aligned with systems theories of 
creativity, deep ecology, and collaboration theory (Lavender, 2009, p.284).

Listening as a rehearsal practice correlates with Lavender's first two pillars of what he describes as dialogical aesthetics. Nonetheless, listening focuses on activating the people involved towards achieving a greater sense of awareness and valuing the participants' inputs. This suggests a distinct form of collaboration grounded in listening, where the $D A R$ approach allows space for contributions from the maker, through directing and navigating a listening process; and the performer, through bringing their agency into it. In this perspective, collaboration may be defined as co-listening: we listen together throughout the process. This framework allows for a constant co-listening activity, which varies throughout the session. When I am directing, the participants listen and respond to my instruction. When they engage in the tasks responding to my direction, they listen to each other and the space, while I listen to them, and the work we produce. When I facilitate dialogical reflections, we all listen to one another. When I choreograph the work in the gallery, making decisions on how the work is shown, I pay attention to the space and the work. While the listening focus-who is listening, and what are they listening toalternates throughout the different activities in the rehearsal, it nevertheless remains continuous, suggesting a constant act of listening, of care. An example of a colistening activity, although not in rehearsal but in the work's appraisal, is Table of Contents by Siobhan Davies (2014). The piece integrates the viewer's presence in the room while constantly negotiating the space and the relationship with the audience. The performance is composed of several parts, and after each section, dancers open a space for dialogue with the audience by inviting the public to gather around a table before performing the next section. The work's immediacy and the connection with the audience through the dialogical activity contribute to the success of the piece. Although in Table of Contents listening to the 
other is tangible in how the work is shown, it is not clear for the viewer whether the listening process was part of the work's making. Perhaps Davies' understanding of dance as a collective activity made by a community (Davies, et al., 2016) manifests in her interest in displaying co-listening moments.
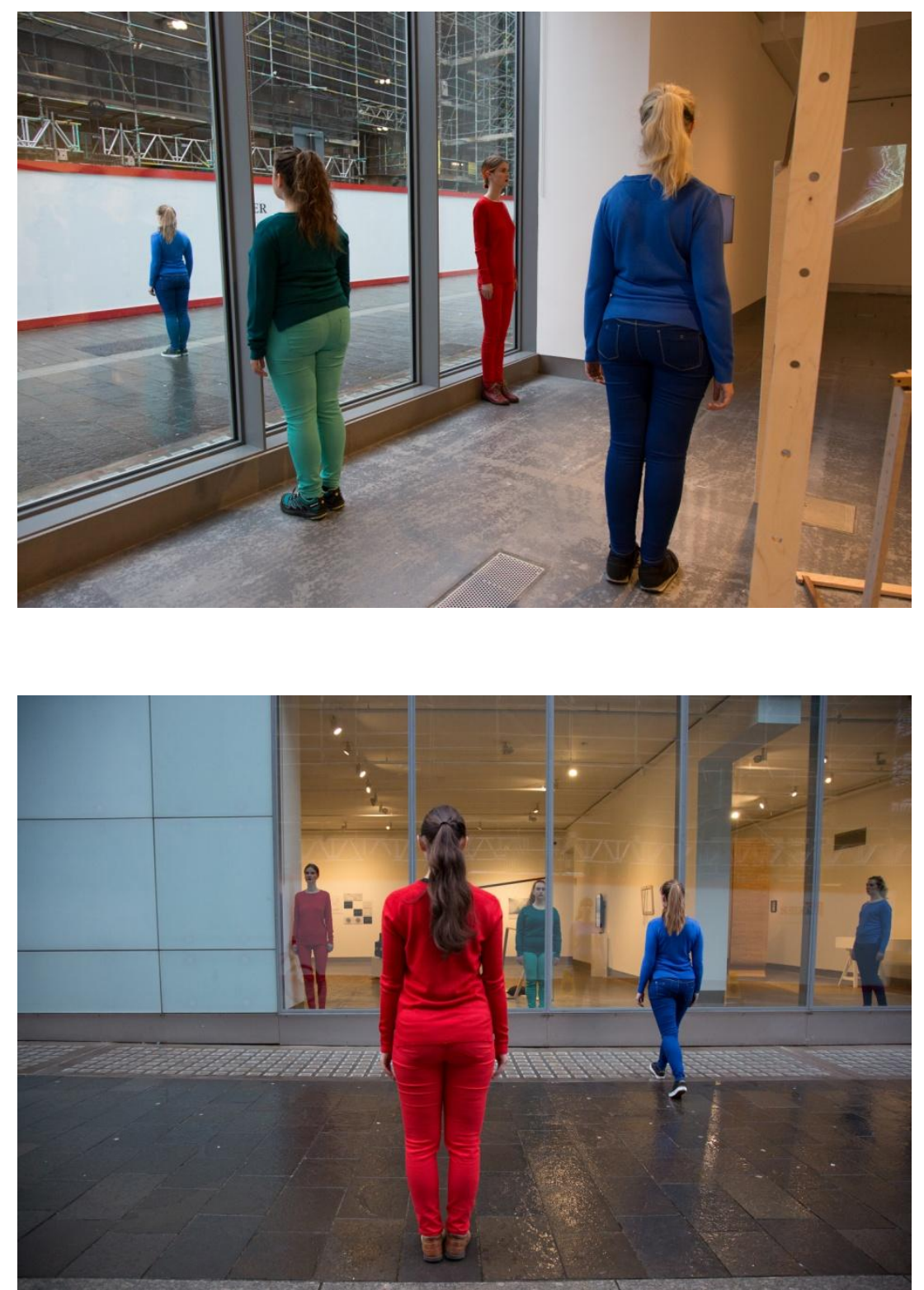

Figures 5 and 6:This is Not About Dance. Window score: inside view (above) and outside view (below). Photos: Jack McCombe.

Although listening during performance remains outside the scope of this paper, it is relevant to note that listening as 
care emerges both in the locations of making and showing throughout the artistic process. This is particularly the case in site-specific practices, as the relationship with space is a key element of the work. During the research stage, I visited the gallery several times to consider how the work may respond to its architectural features. I listened to the possibilities that the gallery environment offers by paying attention to and being present in the space, which I then incorporated in the rehearsal plans. Following two studio rehearsals in This is Not About Dance, the gallery sessions were instrumental in how the work took shape, as a new layer of complexity-listening to the space-was incorporated. In the first gallery rehearsal, the participants' bodies appeared reflected in the windows multiplying the number of performers in the room: this yielded the integration of the windows in the work. As such, I instructed two performers to go outside to test the relationship between outside and inside activity, which later became an integral part of the score, as performers in both spaces interacted with one another (Figs. 5 and 6). Italian architect and author Bruno Zevi (1957) suggests that one can only experience architectural works through spending time in them. He argues that by moving in a building to comprehend it from different points of view, one 'creates, so to speak, the fourth dimension, giving the space an integrated reality' (Zevi, 1957, p.27). Spending time in a site enables one to become more aware of its characteristics, thus gaining a heightened understanding of the space: it becomes a metaphor for being present. Some aspects of a site-specific piece-of which the window sequence is an example-can only be grasped through spending time in the location of its appraisal, allowing space to be perceived as a physical material to be incorporated in the work. As American artist Donald Judd states, 'actual space is intrinsically more powerful and specific than paint on a flat surface' (1965, p.209). Being in the space before, between, and during rehearsals, enables one to grasp the performative nature of the site and incorporate it in the piece. While one may listen to the other both in the dance 
studio and the performance space, the latter allows one to listen to the space itself, offering other potentials for action, particularly in site-specific performance.

\section{Conclusion}

Although in performance practice care often focuses on the wellbeing of the audience and the performance maker when the work becomes public, here, I emphasise care within the rehearsal in performative installation contexts. Conceiving the rehearsal process as a constant act of care opens the door to an understanding of performance making as a conscious act of co-listening, engaging in new forms of collaboration. In considering listening as an integral activity which focuses on developing awareness of our surroundings in performance making-including the other, the space, the work, and the self-listening can also become a metaphor for understanding care as a practice within the rehearsal setting. Operating from a framework of listening to the other, DAR-Direction, Action, and Reflection embedded in care-allows the practitioner to foster an open and ethical environment that supports the participants' agency in the process, as in the rehearsals for This is Not About Dance. In placing performers in a listening framework, one is simultaneously caring for the integrity of the work, and strengthening the relationships between performers and the piece, as participants are the work: their place in the piece relates to who they are and how they feel. Listening as a practice can be applied to other creative fields, opening new possibilities to create through colistening, supporting the growth of one's practice ethically. Considering care in rehearsal as an activity that fosters a colistening approach has implications for makers and performers, a matter beyond the scope of the present study. As this article focuses on listening to the other, the implications of the $D A R$ modus operandi for practitioners and audiences during and after the performance have not been addressed. Further research would allow for an 
understanding of how a practice of listening may be perceived by an audience, and how a constant act of care may be present throughout the entire process.

\section{Funding}

This work is supported by the Portuguese Foundation for Science and Technology (FCT) through the European Social Fund (ESF) and the Human Capital Operational Programme (HCOP).

\section{Acknowledgements}

I wish to thank the wonderful performers Madeleine Virginia Brown, Rowan Flint, Nikki Kane, Monika Smekot, and Donata Vezzato. I am also thankful to Maria Braender, Egan Chan, Kai-Wen Chuang, Nina Enemark, and Enya Zia Fortuna for their valuable input in the initial stages of the project. Further thanks to Jenny Brownrigg, Talitha Kotzé, Caroline Grape, and Jack McCombe at the Reid Gallery for their support throughout the project. It was a pleasure to work with Viviana Checchia, Allyson Keehan, Eszter Biró, Melissa Geraghty, Stephanie Smith and Dr Laura González, with special thanks to Dr Sophia Lycouris. Finally, I am deeply grateful to the FCT Foundation for making this work possible. This article is dedicated to Adrian Howells, whose legacy I have been fortunate to witness.

\section{References}

Becket, S., 1981. Quad. [video online] Available at: 〈https://www.youtube.com/watch?v=4ZDRfnICq9M [Accessed 3 June 2016].

Brown, T., 1971. Walking on the Wall. [online] Available at: 〈https://www.trishabrowncompany.org $/$ ?page=view\&nr=481〉 [Accessed 3 June 2016].

Brown, T., 1975. Locus. In: A. Lepecki ed., 2012. Dance. London: The MIT Press, p.61. 
Buzzarté, M. and Bickley, T., eds., 2012. Anthology of essays on Deep Listening. Kingston: Deep Listening Publications.

Childs, L., 2003. PASTForward choreographers' statements. In: S. Banes ed., 2003. Reinventing dance in the 1960s: everything was possible. Madison: University of Wisconsin Press, pp.193-210.

Colin, N. and Sachsenmaier, S., 2016. Collaborative performancemaking in context. In: N. Colin and S. Sachsenmaier eds., 2016. Collaboration in performance practice: premise, workings and failures. London: Palgrave Macmillan, pp.1-24.

Davies, S., 2014. Table of Contents. [Live performance] Siobhan Davies Dance. 9-10 April 2016, Siobhan Davies Studios, London.

Davies, S., Dodds, R., Irvine, R., Nunn, T., and Setohy, S., 2016. Turner Prize Thursdays: Introducing the visitor audience. [public talk]. 7 January 2016, Tramway, Glasgow.

Eddy, M., 2009. A brief history of somatic practices and dance: historical development of the field of somatic education and its relationship to dance. Journal of Dance and Somatic Practices, 1(1), pp.5-27.

Gold, H., 2012. Deep Listening through movement: a personal history. In: Buzzarté, M. and Bickley, T., eds., 2012. Anthology of essays on Deep Listening. Kingston: Deep Listening Publications, pp.149-152.

Hastings, S. and Wylie, J., 2016. Duty of Care: producing Adrian Howells. In: Heddon, D. and Johnson, D. eds., 2016. It's all allowed: the performances of Adrian Howells. Bristol: Intellect, pp.252-259.

Johnson, D., 2016. Held: an interview with Adrian Howells. In: Heddon, D. and Johnson, D. eds., 2016. It's all allowed: the performances of Adrian Howells. Bristol: Intellect, pp.98-119.

Judd, D., 1965. Specific Objects. In: J. Meyer ed., 2000. Minimalism. London: Phaidon, pp.207-210.

Lavender, L., 2009. Dialogical practices in teaching choreography. Dance chronicle, 32(3), pp.377-411.

Noddings, N., 1984. Caring: a feminine approach to ethics \& moral education. London: University of California Press.

Sander-Staudt, M, n.d. Care Ethics. In: The internet encyclopaedia of philosophy, [online] Available at 〈http://www.iep.utm.edu/care-eth/〉 [Accessed 20 July 2017].

Strauss, E. W., 1966. Phenomenological psychology: the selected papers of Erwin W. Strauss. Translated by E. Eng. London: Tavistock Publications.

Tronto, J., 1993. Moral boundaries: a political argument for an ethic of care. London: Routledge.

Voegelin, S., 2010. Listening to noise and silence: towards a philosophy 
of sound art. London: Continuum.

Zevi, B., 1957. Architecture as space: how to look at architecture. Translated by M. Gendel. New York: Horizon Press.

\section{About the author}

INÊS BENTO-COELHO is a visual artist and PhD candidate at The Glasgow School of Art supported by the Portuguese Foundation for Science and Technology. Her practice-based research explores choreographic approaches in installationart, focusing on space awareness and performativity within site responsive practices. Inês works across performance, installation, and film, and is currently a Graduate Teaching Assistant at The Glasgow School of Art. 